\title{
AVALIANDO O PLANO MUNICIPAL DE EDUCAÇÃO: MONITORAMENTO E CONTROLE SOCIAL
}

\author{
EVALUANDO EL PLAN MUNICIPAL DE EDUCACIÓN: MONITOREO Y CONTROL \\ SOCIAL
}

\section{EVALUATING THE MUNICIPAL EDUCATION PLAN: MONITORING AND SOCIAL CONTROL}

RESUMO: Avaliar e monitorar os Planos Municipais de Educação é um encaminhamento dado pelo Plano Nacional de Educação (2014-2024). Nesse contexto, objetiva-se analisar as ações do Conselho Municipal de Educação e da Secretaria Municipal de Educação, considerando o monitoramento e a avaliação do Plano Municipal de Educação (PME), que culminaram na Conferência Municipal de Educação no município de Jataí, Goiás. Mediante pesquisa documental, com fontes primárias, problematizaram-se as categorias monitoramento e controle social no movimento dialético, entendendo-se que, na democracia liberal, disputam dois projetos educacionais, um para a formação do trabalhador e outro para a formação humana plena. No Estado gerencial, o processo de implementação e avaliação do PME se apresenta, na aparência, de forma democrática, porém, na sua essência objetiva a responsabilização dos envolvidos. Por outro lado, o controle social que conta com a participação da sociedade no processo de monitoramento e avaliação do PME almeja uma qualidade socialmente referenciada.

PALAVRAS-CHAVE: Plano municipal de educação. Controle social. Estado gerencial.

RESUMEN: Evaluar y monitorear los Planes Municipales de Educación es un encaminamiento dado por el Plan Nacional de Educación (2014-2024). En este contexto, se objetiva analizar las acciones del Consejo Municipal de Educación y de la Secretaría Municipal de Educación, considerando el monitoreo y la evaluación del Plan Municipal de Educación (PME), que culminaron en la Conferencia Municipal de Educación en el municipio de Jataí, Goiás. Frente a la investigación documental, con fuentes primarias, se problematizaron las categorías monitoreo y control social en el movimiento dialéctico, comprendiéndose que, en la democracia liberal, disputan dos proyectos educacionales, uno para la formación del trabajador y otro para la formación humana plena. En el Estado gerencial, el proceso de implementación y evaluación del PME se presenta, en la apariencia, de forma democrática, en pero, en su esencia objetiva y responsabilidad de los involucrados. Por otro lado, el control social que cuenta con la participación de la sociedad en el proceso de monitoreo y evaluación del PME anhela una cualidad socialmente referenciada.

PALABRAS CLAVE: Plan municipal de educación. Control social. Estado gerencial.

${ }^{1}$ Universidade Federal de Goiás (UFG), Jataí - GO - Brasil. Professora de graduação e pós-graduação. Doutorado em Educação pela UFU. ORCID: http://orcid.org/0000-0003-4359-5828. E-mail: elizabethraimann@gmail.com 
ABSTRACT: Evaluating and monitoring the Municipal Education Plans is a referral given by the National Education Plan (2014-2024). In this context, the objective is to analyze the actions of the Municipal Education Council and the Municipal Education Secretariat, considering the monitoring and evaluation of the Municipal Education Plan (PME), which culminated in the Municipal Education Conference in the municipality of Jataí, Goiás. Through documentary research, with primary sources, the categories monitoring and social control in the dialectical movement were problematized, understanding that, in liberal democracy, they dispute two educational projects, one for the training of the worker and the other for the complete human formation. In the managerial State, the process of implementing and evaluating the PME presents itself, in appearance, in a democratic way, however, in essence it objective the accountability of those involved. On the other hand, the social control that counts on the participation of society in the process of monitoring and evaluating the PME aims at a socially referenced quality.

KEYWORDS: Municipal education plan. Social control. Managerial state.

\section{Introdução}

Este artigo objetiva analisar as ações do Conselho Municipal de Educação (CME) e da Secretaria Municipal de Educação (SME), considerando o monitoramento e a avaliação do Plano Municipal de Educação (PME), que culminaram na Conferência Municipal de Educação, no município de Jataí, Goiás, em 2017.

A análise dos dados é um recorte dos resultados de uma pesquisa interinstitucional, em desenvolvimento, intitulada "Implementação e controle social dos Planos Municipais de Educação: a atuação dos Conselhos Municipais de Educação no Brasil”. Esta Investigação aglutina grupos de pesquisa em cinco instituições de ensino superior localizadas na região Centro-Oeste e Triângulo Mineiro, que compõem o GEP-CMEBr - Grupo de Estudos e Pesquisa dos Conselhos Municipais de Educação no Brasil.

Avaliar e monitorar os PME, durante o decênio de 2015-2025, é encaminhamento dado pelo próprio Plano Nacional de Educação (PNE). Na ocasião de sua aprovação, instituiu-se a Secretaria de Articulação com os Sistemas de Ensino (SASE) para dar o apoio técnico necessário aos municípios, durante o processo de (re)elaboração dos PME, bem como no acompanhamento dos planos, a fim de avaliar e monitorar as metas e estratégias propostas ao longo da década e assim se poder alcançar a qualidade da educação no país.

Nesse contexto, a pesquisa, de cunho documental, fez uso de fontes primárias como relatórios da comissão de monitoramento e avaliação do PME (2016-2017) e convocação da SME à audiência pública para a Conferência Municipal de Educação, em 2017, avaliando o primeiro biênio do PME do município de Jataí/GO. 
Justificando a relevância de se acompanhar a implementação de políticas educacionais nos dias atuais, buscar-se-á trazer a contribuição de pesquisadores sobre a temática, considerando o que se pode denominar por policy analysis (FREY, 2000) ou policy (PEREZ, 2008). Na sequência, no movimento dialético, o exame das categorias monitoramento e controle social no Estado gerencial; e, por último, a análise dos dados referentes às ações do CME e da SME para a Conferência Municipal de Educação.

\section{A implementação de políticas educacionais: avaliando e monitorando o PME}

A Lei nº 13.005, de 25 de junho de 2014, que instituiu o Plano Nacional de Educação, prevê o monitoramento e a avaliação, durante o decênio, não somente do plano nacional, mas também dos planos municipais. Na lei, em seu artigo quinto, estabeleceram-se as instâncias responsáveis para tal fim, visando alcançar as 20 metas propostas e suas respectivas estratégias. No artigo oitavo, estabeleceu-se que estados, Distrito Federal e municípios (re)elaborem seus respectivos planos em consonância com o nacional, a fim de que fossem garantidas as diretrizes do plano nacional. (BRASIL, 2014).

Durante esse processo, houve a mobilização do Ministério da Educação (MEC) em conjunto com a Secretaria de Articulação com os Sistemas de Ensino (SASE) no empenho de que cada município pudesse construir o seu Plano Municipal de Educação. A assistência técnica do MEC via SASE, em conjunto com a União Nacional dos Dirigentes Municipais de Educação (UNDIME) e a União Nacional dos Conselhos Municipais de Educação (UNCME) possibilitou articular programa e ações para a discussão e elaboração dos PME em cada cidade. Com o PNE (2014-2024) aprovado, coube aos 5.570 municípios brasileiros não apenas a elaboração de seus PME, mas também a realização de ações para a devida implementação dos referidos planos.

A SASE teve um importante protagonismo, naquele momento, pois uma de suas funções era dar o apoio técnico ao trabalho dos Dirigentes Municipais, das equipes técnicas e das Comissões designadas na elaboração dos PME.

Dentre as ações de apoio, foi preparado o documento Plano Municipal de Educação: Caderno de Orientações (BRASIL, 2014b), objetivando auxiliar as comissões municipais a elaborarem e a implementarem seus respectivos planos. Desta forma, a SASE teve como função estimular a participação de diversos setores da sociedade para que o PME, de uma mera formalidade burocrática, passasse a ser um documento elaborado pelo coletivo da comunidade, apontando para o controle social, pois, para além da construção do plano, haveria a necessidade do acompanhamento social para a sua efetivação. 
Conforme as orientações do Caderno, para se obter o sucesso do PME, é preciso que este tenha legitimidade, e esclarece:

Planos construídos em gabinetes ou por consultores alheios à realidade municipal tendem ao fracasso, mas um PME submetido ao amplo debate incorpora a riqueza das diferentes visões e vivências que a sociedade tem sobre a realidade que deseja alterar (BRASIL, 2014, p. 8).

Seguindo a mesma metodologia, agora para o monitoramento e avaliação dos planos municipais, em 2016, o MEC organizou outro Caderno de Orientações, denominado "PNE em movimento". Nele encontram-se os encaminhamentos, passo a passo, para que as instâncias responsáveis como Conselho Municipal de Educação, Secretaria Municipal de Educação e Fórum Municipal de Educação possam estabelecer uma comissão e equipe técnica para o acompanhamento sistemático da execução do PME e sua avaliação. A fim de esclarecer o que seja o processo de monitoramento e avaliação do PME, o Caderno de Orientações apresenta:

Monitorar e avaliar são etapas que se articulam continuamente em um único processo, contribuem para o alcance das metas propostas, apontam as lacunas e eventuais mudanças necessárias no percurso e incorporam ao plano o caráter de flexibilidade necessário para absorver as demandas da sociedade (BRASIL, 2016, p. 6).

Nesse sentido, a proposta acima objetiva uma análise constante da realidade educacional do município, apontando para a necessidade de diálogo entre o executivo municipal, a comissão designada para o monitoramento e avaliação do PME e a sociedade.

Para que o processo fosse sistematizado, o Caderno de Orientações apresenta uma ficha de monitoramento, em três etapas. Esta ficha, a princípio um modelo, é implementada pela SASE que acompanha cada município, para que os dados solicitados sejam enviados e que os prazos estabelecidos sejam, de fato, observados dentro de um cronograma anual.

O destaque na ficha está em que cada meta, com as suas respectivas estratégias, deve ser descrita e avaliada, ou seja, se está dentro dos prazos estabelecidos bem como seus indicadores. Os dados levantados pela ficha devem, posteriormente, subsidiar a avaliação do PME, mediante a audiência pública, dando assim o caráter participativo e democrático, bem como o controle social do PME.

Nesse sentido, o Caderno afirma que a avaliação do PME resultará em uma versão preliminar. E esclarece:

Versão Preliminar será o subsídio mais importante para o debate nas audiências públicas de avaliação dos resultados alcançados, por isso, a avaliação deve ser elaborada e debatida com muito cuidado e seriedade. Dela 
poderão derivar recomendações para a alteração da lei do plano. Por essa razão, o dirigente municipal, as unidades de ensino, as equipes técnicas da prefeitura, os parlamentares e as representações da sociedade em geral deverão estar muito atentos e preparados para o debate (BRASIL, 2016, p. 11, grifo no documento).

A avaliação do PME deve ser, a critério do município, bienal ou trienal, auxiliando na tomada de decisões, por parte dos dirigentes municipais, para melhorar a qualidade socialmente referenciada da educação, conforme recomenda o Caderno:

[...] de monitoramento contínuo e avaliação periódica, deve significar uma oportunidade de melhorar a qualidade técnica do diagnóstico, de ampliar a participação social e de qualificar ano a ano a execução das metas. Deve ser entendido como exercício contínuo de aproximação da gestão ao desejo da sociedade, em um trabalho coletivo e democrático, em que o estudante é o grande beneficiado (BRASIL, 2016, p. 4).

A descrição do processo de elaboração e implementação do PME até aqui, a partir das orientações do MEC, devem ser compreendidas como parte da política educacional no país, considerando o caráter do PNE ser uma política educacional de estado e não de governo. Diante disso, as contribuições de Frey (2000) e Perez (2008), a seguir, auxiliam a compreender a importância da pesquisa sobre a implementação das políticas sociais.

Frey (2000), a partir do campo teórico metodológico, discute as possibilidades de análise de políticas públicas no Brasil. Apresenta três abordagens de análise: o sistema político, as forças políticas no sistema decisório e os resultados obtidos. Em sua análise, o autor avança, esclarecendo que a policy analysis faz uma inter-relação entre as três abordagens e apresenta, além de seus conceitos básicos, os limites de pesquisa. Nesse sentido, a policy analysis ampliase na compreensão a partir de outras categorias, como policy network, policy arena, policy cycle, levando em conta a dimensão institucional e a processual (FREY, 2000).

Perez (2010), por sua vez, justifica a importância e a necessidade de se pesquisar a implementação de políticas educacionais. $\mathrm{O}$ autor identifica quatro fases da política educacional, sendo elas: agenda, formulação, implementação e avaliação.

Sobre a implementação, aponta para duas vertentes: uma que percebe o processo iniciado pela política até o seu impacto, e a segunda, que tem a compreensão de um processo que "envolve uma série de decisões e ações postas pela autoridade legislativa central” (p. 1181). Perez (2010) aponta para quatro aspectos aos quais esse tipo de pesquisa pode contribuir. São eles:

1) visam corrigir o curso das ações, fornecendo subsídios aos implementadores durante o curso da política, em razão de suas 
características de policy oriented; 2) buscam ampliar a efetividade do processo de decisão dos programas públicos; 3) contribuem para ampliar a accountability dos programas; 4) ampliam a integração dos corpos administrativo, político e comunidade, fundamentais para a mudança do desempenho educacional. (p. 1181, grifos do autor).

O autor considera as dificuldades em torno da implementação de políticas, pois segundo ele, a operacionalização da política transformada em programa pode apresentar dificuldades em nível local, uma vez que existem "os obstáculos e os elementos facilitadores, assim como o grau de adesão e resistência dos agentes implementadores” (PEREZ, 2010, p. 1189).

Na percepção do autor, para se analisar a implementação de políticas educacionais, é preciso buscar articulações entre o micro e macroprocesso. Desta forma, Perez (2010) apresenta três dimensões:

A primeira dimensão trata das relações entre o desenho ou a formulação da política, de um lado, e os formatos que os programas adquirem ao final do processo, de outro. A segunda é a dimensão temporal do processo e seus efeitos diferenciados no tempo sobre a organização em que se processam, sobre os atores que implementam (resistências e adesões) e as modificações das condições iniciais. A terceira refere-se às condições que propiciam ou entravam o processo de implementação (p. 1189).

As ponderações dos autores sobre os limites e possibilidades na pesquisa em políticas públicas desvelam que o processo de implementação de determinada política social possui variantes, fatores que irão interferir para que ela se concretize ou não a partir de como foi formulada. Por outro lado, ao se pesquisar a implementação de políticas educacionais, é preciso considerar que há, na sociedade capitalista, projetos educacionais antagônicos e que estes estão em disputa constantemente. Daí que a formulação, implementação e avaliação do PME se dará em um espaço de conflito e não de consenso, pois a racionalidade tanto democrática quanto a financeira (SAVIANI, 1999) estará presente, permeando todo o processo. Ou seja, na proposição do PME de Jataí/GO, documento base, buscou-se a participação da sociedade, para que se pudesse ter um plano de educação que, de fato, atendesse os anseios da população, uma educação de qualidade socialmente referenciada. No entanto, quando de sua aprovação, enquanto projeto de lei, prevaleceu-se a racionalidade financeira por parte do executivo municipal. (RAIMANN; OLIVEIRA; RAIMANN, 2019). 


\section{O Estado gerencial: monitoramento e controle social}

A racionalidade financeira, que acompanhou a reforma da administração do Estado, muda a feição deste Estado, que de bem-estar social se transforma em Estado gerencial. Este se caracteriza como aquele que é regido por princípios de gestão por resultados, buscando a qualidade de seus serviços com eficiência e eficácia, reduzindo gastos e otimizando recursos, descentralizando suas ações para centralizar na avaliação dos resultados. No Estado gerencial, o cidadão passa a ser cliente/usuário, que avalia os serviços prestados, inserindo-se na cultura da responsabilização.

A reforma da administração do Estado implementada durante o governo de Fernando Henrique Cardoso, década de 1990, pelo então ministro Bresser Pereira, propôs a reforma gerencial. Segundo Bresser Pereira (1997), é preciso intervir em quatro problemas, que seriam “(a) [...] a delimitação do tamanho do Estado; (b) [...] a redefinição do papel regulador do Estado; (c) [...] a recuperação da governança [...] e (d) [...] o aumento da governabilidade" (p. 7). Nesse paradigma de gestão gerencial pública, dever-se-ia distinguir o que seriam as atividades exclusivas do Estado em detrimento dos serviços sociais, científicos e culturais; considerar a publicização, além "das principais formas de controle ou coordenação econômica e social existentes no capitalismo contemporâneo" (BRESSER PEREIRA, 1997, p. 8).

Considerando o controle social, na perspectiva do estado gerencial, Bresser Pereira afirma serem os mecanismos de controle "além do sistema jurídico que antecede a todos: (1) mercado, (2) controle social (democracia direta), (3) controle democrático representativo, (4) controle hierárquico gerencial, (5) controle hierárquico burocrático e (6) controle hierárquico tradicional" (1997, p. 37). Aqui o destaque para a democracia direta, ou seja, "através do controle social a sociedade se organiza formal e informalmente para controlar não apenas os comportamentos individuais, mas - e é isto que importa neste contexto - para controlar as organizações públicas" (1997, p. 38).

O controle social, nesta perspectiva, ganha sua relevância por contribuir para a governança, ou seja, a fiscalização dos serviços prestados pelo poder público será realizada pelo cidadão cliente. Nessa perspectiva, a educação enquanto serviço, e não como bem social, será controlada pelo cidadão/usuário.

Por fim, Bresser Pereira (1997) apresenta que no Estado gerencial, para a sua governabilidade, é preciso existirem mecanismos de responsabilização, também denominados por accuntability. Isso significa dizer que tanto governo quanto servidor público, responsável 
por determinado programa, ação ou serviço prestado à população, possa prestar contas das suas ações e dos resultados obtidos ou não, da sua eficiência e eficácia ou não.

Nessa direção, Silva et al (2018), objetivando analisar a atuação dos conselhos municipais na região Nordeste do Brasil, tendo como base as fiscalizações realizadas pela Controladoria-Geral da União, tomando como contexto a reforma gerencial, o controle social e a responsabilização, afirmam que:

Essa ideia de controle social trouxe mudanças para a comunidade, alterando seu papel meramente passivo de recebedora de serviços do Estado para a condição colaborativa e participativa das decisões políticas. Assim, a nova responsabilidade da sociedade civil se fez reverberar pelo seu envolvimento concomitante com a atuação do poder público no combate à corrupção e, também, pela sua participação prévia em debates de interesse da coletividade e na priorização das políticas públicas voltadas aos grupos sociais (2018, p. $75)$.

Souza e Alcântara (2017), ao se proporem a analisar a atuação dos Conselhos Municipais de Educação no monitoramento e avaliação dos PME da região metropolitana do Rio de Janeiro, ponderam que esse processo de monitoramento e avaliação nas políticas públicas apresenta vertentes tanto políticas quanto de gerenciamento. Considerando que monitorar e avaliar estão ligados entre si, asseveram que

[...] o monitoramento não se encontra dissociado do instrumento de avaliação propriamente dito, estando articulado aos seus fins. É por meio do monitoramento que a avaliação da política é viabilizada, na medida em que passa a dispor de dados para serem analisados com vistas ao replanejamento da ação pública [...] o que configura ambos os processos como complementares (SOUZA; ALCÂNTARA, 2017, p. 490).

Nesse sentido, para além do caráter gerencial, que busca a efetividade, a eficácia e a eficiência da política implementada, é possível analisar e redimensionar as ações, visando às transformações propostas, mediante mecanismos democráticos.

Dentre as instâncias institucionalizadas nas esferas federal, estadual e municipal, que possibilitam efetivas ações democráticas, estão os conselhos municipais, que se abrem como possíveis espaços de participação e controle social.

Em se tratando dos conselhos municipais e de sua formação, Silva et al., (2018) esclarecem sobre sua estrutura e funcionamento, como se lê:

Suas estruturas integram a esfera pública e política, com o intuito de mediar relações, mitigar conflitos e conferir maior interação entre governo e sociedade civil. São constituídos com objetivo de deliberar e definir políticas 
públicas específicas, a exemplo da educação básica, saúde, meio ambiente, patrimônio histórico-cultural, entre outras. Compõem-se por representantes do poder público e da sociedade civil organizada, que formulam, em conjunto, as políticas públicas em um processo de gestão descentralizada e participativa, resultando em uma maior cobrança na prestação de contas por parte dos gestores públicos (p. 78).

Apesar de o Conselho Municipal de Educação ser um órgão instituído pelo poder público, sua atuação na implementação e controle social do PME, em uma perspectiva democrática, mediando interesses e conflitos, pode ampliar ações de natureza social, enfrentando e combatendo as ações burocráticas do Estado que, via de regra, exerce forte controle gerencial em suas ações.

Nessa perspectiva, a participação social constitui-se como instrumento de controle social e político do Estado pela sociedade. Em se tratando do PME, tal participação dá aos cidadãos a possibilidade de atuarem efetivamente, definindo rumos e critérios para a ação pública, na busca de uma educação de qualidade socialmente referenciada.

As categorias monitoramento e controle social podem ser compreendidas como forma de controle estatal, na perspectiva gerencialista, mas também como efetiva forma de participação social nas tomadas de decisões no que a população almeja enquanto bem social.

\section{Avaliando o Plano Municipal de Educação de Jataí/GO}

Seguindo as determinações da Lei $\mathrm{n}^{\circ}$. 13.005/2014 (BRASIL, 2014), conforme seu artigo oitavo, Jataí, assim como os demais municípios do país, elaborou e aprovou o seu primeiro PME, Lei no . 3.708, de 26 de junho de 2015 (JATAÍ, 2015).

Durante o processo de elaboração do PME, foi instituída uma comissão de trabalho. Inicialmente sob a coordenação do Conselho Municipal de Educação e, posteriormente, com o apoio da Secretaria Municipal de Educação, esta comissão foi ampliada, bem como formada uma equipe técnica, seguindo as orientações da SASE.

A comissão de elaboração do PME contou com a participação de vários segmentos da sociedade, dividindo-se os trabalhos em equipe técnica, grupo gestor e colaboradores. As representações que se fizeram presentes foram Secretaria Municipal de Educação, Subsecretaria Regional de Educação, CME, Conselho Comunitário, Escolas privadas, Instituto Federal de Educação, Ciências e Tecnologia de Goiás/Campus Jataí (IFG), Universidade Federal de Goiás/Regional Jataí (UFG/REJ), Universidade Estadual de Goiás/Jataí, SINTEGO/Regional Jataí (JATAÍ, 2015). 
Quase um ano após a aprovação do PME em forma de lei, no mês de maio de 2016, a SME institui, mediante portaria, a Comissão de Monitoramento e Avaliação do PME com as representações da SME, Subsecretaria Regional de Educação, do Administrativo e do CME, conforme consta no primeiro relatório da Comissão disponibilizado no sítio da Prefeitura Municipal de Jataí/GO (RELATÓRIO, 2016).

Esta comissão convidou representantes dos diferentes segmentos públicos e privados para colaborar com os trabalhos. Fizeram parte professores(as) da rede municipal, estadual e privada, do ensino superior (Universidade Estadual de Goiás/Jataí, Universidade Federal de Goiás/Regional Jataí, Instituto Federal de Goiás/ Campus Jataí, SENAI, SENAC e SESI), Representantes da SME, da Subsecretaria Regional de Educação, Centro de Atendimento Educacional Especializado, Conselho Municipal de Educação, Conselho Municipal da Criança e do Adolescente, Sindicato dos Trabalhadores da Educação de Goiás (SINTEGO), Câmara Municipal.

A SASE, naquele momento, prestou assistência, conforme relatório, mediante adesão do município à proposta (RELATÓRIO, 2016). Iniciou-se, desta forma, um processo de formação para a comissão ampliada, instruindo aos participantes como avaliar as metas e estratégias, como preencher as fichas de monitoramento, bem como, caso fosse necessário, elaborar notas técnicas. Havia prazos estabelecidos e cobranças por parte da SASE.

Esse processo continua no ano seguinte. Porém, com a alternância do poder na gestão municipal, houve alterações na coordenação da Comissão. Mudanças significativas, de teor político. Ainda assim, na condução do monitoramento e avaliação do PME, a continuidade do processo ocorreu sem rupturas. O relatório de 2017, bem mais técnico, apresenta a comissão coordenadora de monitoramento e avaliação ampliada, nominalmente, e com portaria de designação. Neste relatório as representações permanecem, porém com mais representantes das escolas municipais, urbana e rural, e dos centros municipais de educação infantil.

Em 2017 estava prevista a primeira avaliação do PME, e a secretária municipal de educação assume a responsabilidade de, ao final do ano, apresentar o PME à comunidade para, em audiência pública, discuti-lo e avaliá-lo.

A data escolhida para esta atividade foi no final do ano letivo, 18 de dezembro: os alunos teriam sido dispensados para as férias escolares e os professores e demais funcionários da educação ainda estariam em atividades.

No início do mês de dezembro, foi publicado no sítio da Secretaria Municipal de Educação o convite/convocação com o título: 'Audiência Pública sobre o Monitoramento e 
Avaliação do Plano Municipal de Educação do município será realizada no mês de dezembro' (AUDIÊNCIA, 2017)

A escolha do dia e da programação da audiência não passou pela discussão da Comissão de monitoramento e avaliação do plano. Foi uma escolha unilateral por parte da secretaria municipal, tanto a escolha do palestrante quanto os locais para a condução das discussões das metas. Na prática, significa dizer que a mobilização para a audiência ocorreu em um momento em que a comunidade escolar já estava cansada, no entanto, precisaria estar presente, pois como funcionários da Secretaria Municipal de Educação deveriam assinar a presença no dia.

A programação ocorreu nos turnos matutino e vespertino, das 7 às 17 horas, primeiro com palestra no Centro de eventos do município para todos os participantes e à tarde, nas escolas municipais designadas, com cada uma das metas e estratégias sendo discutidas. $\mathrm{O}$ relator de cada meta deveria anotar as discussões e proposições feitas pelos participantes em ficha específica, depois, ao final, todos assinariam no formato de ata. Esse documento foi recolhido e, posteriormente, seria analisado e incorporado ao relatório do ano de 2018. A audiência foi noticiada no sítio da prefeitura do município, como se lê:

A Prefeitura de Jataí, por meio da Secretaria de Educação, realizou durante toda essa segunda-feira (18), ações com objetivo de analisar e debater sobre monitoramento e avaliação do Plano Municipal de Educação do município PME (2015-2025). [...] foram realizadas oficinas temáticas nas salas das escolas municipais, Isabel Franco Moraes e Silva, Isaías Soares, Professor João Justino de Oliveira (CAIC) e Antônio Tosta, onde foram abordadas questões sobre o cumprimento das 20 metas e as estratégias que fazem parte da vigência do plano (PREFEITURA, 2017).

Foram atividades intensas, mas o debate, por parte dos participantes, nas oficinas, pouco acrescentou na qualidade das análises das metas e suas estratégias. Mesmo com o PME disponibilizado no sítio da SME, dos muitos participantes poucos foram aqueles que tinham conhecimento e interesse no teor do PME.

O monitoramento do PME realizado pela Comissão designada teve grandes dificuldades em ter acesso aos dados no seu primeiro ano, havia pouca vontade política por parte do poder local, pois era ano de eleições. No segundo ano, houve empenho um pouco maior, por parte da secretaria municipal, em fazer com que a comissão avançasse na obtenção dos dados para preencher o relatório de monitoramento e avaliação, isso fica perceptível ao se comparar os dois relatórios $(2016,2017)$.

Considerando o protagonismo do CME e da SME no processo de elaboração, implementação e avaliação do PME, pode-se dizer que, durante a elaboração do PME, o CME 
se destacou, envolvendo a participação dos representantes da sociedade e um público considerável na audiência pública para a aprovação do documento base do PME.

No segundo ano de monitoramento e avaliação do PME, até a audiência pública para avaliação do PME, 2017, o protagonismo foi da SME. Isso é percebido conforme noticiado, sobre a audiência pública, no sítio da prefeitura. Como se lê:

\begin{abstract}
A secretária de Educação, falou sobre a felicidade de estar vivenciando este momento histórico da educação de Jataí, parabenizando o brilhante trabalho que os servidores da secretaria de Educação fizeram para que o evento acontecesse, se mostrando grata a cada um que esteve presente. Em sua fala, o prefeito [...] cumprimentou a todos, reconhecendo a contribuição de cada uma das pessoas, para discutirem o presente e o futuro da educação em Jataí. O prefeito também relatou, que o primeiro grande evento do início da sua administração foi a abertura do ano letivo da educação e que agora tem o prazer de encerrar este ano com mais um evento da educação lotado, que marca o encerramento de 2017. Além disso, disse que considera uma honra ter convocado a audiência pública, que é a primeira reunião popular de avaliação do plano municipal de educação do nosso município e garantiu que, a cada dois anos, este será novamente avaliado, executando a lei de vigência do Plano, que norteia os esforços públicos e privados em direção à garantia da educação de qualidade - que vai desde a educação infantil ao ensino superior - para todos os cidadãos jataienses (PREFEITURA, 2017).
\end{abstract}

As falas dos dois representantes públicos municipais, secretária e prefeito, podem ser compreendidas como se quisessem prestar contas à comunidade educacional de sua atuação junto ao monitoramento e a avaliação do PME, ou seja, na perspectiva gerencial, apresentam as ações e os resultados obtidos, sua eficiência e eficácia.

A presença dos profissionais da educação nesta audiência pública para avaliar o PME não passou de um participacionismo, bem diferente daquela por ocasião da aprovação do documento base do PME para ser encaminhado ao executivo, em 2015, quando de fato houve uma participação efetiva. Este participacionimo se deve ao formato da própria convocação/convite, por parte da SME, para o evento.

Além do mais havia por parte dos profissionais da educação uma desmotivação, desmobilização, que se acredita que seja fruto de dois momentos distintos. O primeiro, quando do PME aprovado enquanto lei, este não foi o que a audiência pública referendou, houve disputa entre dois projetos educacionais antagônicos, prevalecendo a racionalidade financeira em detrimento da democrática. O segundo, a própria realidade educacional do país, pois em 2016 o governo federal aprovava a 'PEC da morte', ou seja, o corte nos investimentos na educação por 20 anos. 


\section{Considerações finais}

Ao se analisar as ações do Conselho Municipal de Educação e da Secretaria Municipal de Educação nos relatórios de monitoramento e avaliação do PME, 2016 e 2017, culminando na Conferência Municipal de Educação no município de Jataí/GO, em dezembro de 2017, percebeu-se que a realidade municipal e nacional interferiu no andamento da comissão de monitoramento, bem como no acompanhamento social para a sua efetivação.

As mudanças de ordem local, com a alternância do governo municipal, apesar de a comissão e a sua representatividade não terem sido alteradas no processo de transição. Desde o início dos trabalhos a comissão teve dificuldades no acesso aos dados estatísticos do município, pois estes não se encontravam em domínio público. A Secretaria Municipal de Educação, mesmo que tenha assumido a sua responsabilidade junto ao monitoramento e avaliação do PME, não o fez nos moldes de uma gestão democrática. A comissão de monitoramento em alguns momentos ficou à margem das decisões como, por exemplo, na promoção da audiência pública para avaliar o PME.

O cenário político nacional, com o governo federal impondo um corte no investimento educacional por 20 anos, também desmotivou e desmobilizou os profissionais da educação em torno do PME, uma vez que o próprio plano municipal também já tinha sofrido cortes por parte do executivo quando de sua aprovação.

Quanto às categorias monitoramento e controle social, no movimento dialético, compreende-se que, na democracia liberal, disputam dois projetos educacionais, um para a formação do trabalhador e outro para a formação humana plena. No Estado gerencial, o processo de implementação e avaliação do PME, se apresenta, na aparência, de forma democrática; porém, na sua essência, objetiva a responsabilização dos envolvidos na lógica gerencial. Por outro lado, o controle social, enquanto uma participação efetiva e democrática da sociedade no processo de monitoramento e avaliação do PME, almeja uma qualidade da educação socialmente referenciada.

\section{REFERÊNCIAS}

BRASIL. Lei n. 13.005, de 25 de junho de 2014. Aprova o Plano Nacional de Educação PNE e dá outras providências. Diário Oficial da União, Brasília, DF: Poder Legislativo, 26 jun. 2014. Disponível em: http://www.planalto.gov.br/ccivil_03/_ato20112014/2014/lei/113005.htm. Acesso em: 4 out. 2019. 
BRASIL. O Plano Municipal de Educação. Caderno de Orientações. Ministério da Educação / Secretaria de Articulação com os Sistemas de Ensino (MEC/ SASE), 2014.

BRASIL. O PNE em movimento. Caderno de Orientações para o monitoramento e avaliação dos Planos Municipais de Educação. Brasília: MEC, 2016.

BRESSER PEREIRA, L. C. A reforma do estado dos anos 90: lógica e mecanismos de controle. Brasília: Ministério da Administração Federal e Reforma do Estado, 1997. 58 p. (Cadernos MARE da reforma do estado; v. 1).

FREY, K. Políticas públicas: um debate conceitual e reflexões referentes à prática da análise de políticas públicas no Brasil. Planejamento e políticas públicas, n. 21, p. 211-259, jun. 2000. Disponível em: http://www.ipea.gov.br/ppp/index.php/PPP/article/view/89. Acesso em: 4 out. 2019.

\section{JATAÍ. Audiência Pública sobre o Monitoramento e Avaliação do Plano Municipal de} Educação do município, 18 dez. 2017. Disponível em: http://www.jatai.go.gov.br/prefeiturade-jatai-realiza-audiencia-publica-sobre-o-monitoramento-e-avaliacao-do-plano-municipalde-educacao-do-municipio/. Acesso em: 4 out. 2019.

JATAÍ. Audiência sobre o Plano Municipal De Educação. 2017. Disponível em: http://www.jatai.go.gov.br/?s=+audiencia+publica+plano+municipal+de+educa\%C3\% A7\% C 3\%A3o. Acesso em: 3 out. 2019.

JATAÍ. Lei n. 3.708 de 26 de junho de 2015. Aprova o Plano Municipal de Educação - PME para o próximo decênio, e dá outras providências. Diário Oficial Eletrônico do Município de Jataí, Jataí, GO, ano 3, n. 516, p. 1-22, jun. 2015. Disponível em: http://sislegis.camarajatai.go.gov.br/portal/seeker?iddoc=5049. Acesso em: 20 abr. 2018.

PEREZ, J. R. R. Por que pesquisar implementação de políticas educacionais atualmente? Educação e Sociedade, Campinas, v. 31, n. 113, p. 1179-1193, out./dez. 2010. Disponível em: http://www.scielo.br/pdf/es/v31n113/07.pdf. Acesso em: 4 out. 2019.

RAIMANN, E. G.; OLIVEIRA, C. A. V de.; RAIMANN, A. Plano Municipal de educação: reflexões acerca de um projeto em disputa. Educação e Mundo do Trabalho: m defesa da escola pública. XI Seminário Nacional HISTEDBR, IV Seminário Internacional Desafios do trabalho e Educação no século XXI, I Seminário Internacional HISTEDBR. 2019. Anais[...] Uberlândia: Navegando, 2019, p. 152. Disponível em:

https://www.semintertrabedu.com.br/anais. Acesso em: 4 out. 2019.

RELATÓRIO. Monitoramento e avaliação do PME, 2016. Disponível em: http://www.jatai.go.gov.br/secretaria-de-educacao/plano-municipal-de-educacao/. Acesso em: 4 out. 2019.

RELATÓRIO. Monitoramento e avaliação do PME, 2017. Disponível em: http://www.jatai.go.gov.br/secretaria-de-educacao/plano-municipal-de-educacao/. Acesso em: 4 out. 2019. 
SAVIANI, D. Sistemas de ensino e planos de educação: no âmbito dos municípios. Educação \& Sociedade, Campinas, ano XX, n. 69, p. 119-136, dez. 1999. Disponível em: http://www.scielo.br/pdf/es/v20n69/a06v2069.pdf. Acesso em: 30 jul. 2019.

SILVA, R. M. P. de; GONÇALVES, A. de O.; SANTOS, A. C.; PIRKIEL, E. C. Controle social: a atuação dos conselhos municipais da região Nordeste. Gestão \& Regionalidade, São Caetano do Sul, v. 34, n. 101, maio/ago. 2018. Disponível em:

http://seer.uscs.edu.br/index.php/revista_gestao/article/view/4067. Acesso em: 4 out. 2019.

SOUZA, D. B; ALCÂNTARA, A. B. Conselho Municipal de Educação: monitoramento e avaliação dos Planos Municipais de Educação relativos ao Plano Nacional de Educação 20142024. Revista Contrapontos [eletrônica], Itajaí, v. 17, n. 3, p. 485-508, jul./set. 2017.

\section{Como referenciar este artigo}

RAIMANN, Elizabeth Gottschalg. Avaliando o plano municipal de educação: monitoramento e controle social. Revista Ibero-Americana de Estudos em Educação, Araraquara, v. 15, n. esp. $1, \quad$ p. 810-824, maio 2020. e-ISSN: 1982-5587. DOI: https://doi.org/10.21723/riaee.v15iesp.1.13351

Submetido em: 30/10/2019

Revisões requeridas: $10 / 11 / 2019$

Aprovado em: 20/12/2019

Publicado em: 30/04/2020 